\title{
Asset Allocation, Heterogeneity and Consumption
}

\author{
Liping Wang* \\ School of Economics \\ Shandong University of Finance and Economics \\ Jinan, P.R. China
}

\author{
Xue Meng \\ School of Economics \\ Shandong University of Finance and Economics \\ Jinan, P.R. China
}

\begin{abstract}
This paper defines the heterogeneous consumers according to the ratio between the high liquid assets and income, and uses the data from the China Family Panel Studies (CFPS) of 2010, 2012, 2014 and 2016 to examine the response of heterogeneous consumers to the temporary income shocks and the wealth effects of the assets on the heterogeneous consumers. The study shows that consumers are more vulnerable to temporary income shocks when they have insufficient high liquid assets, and the wealth effect of the housing assets differ among the heterogeneous consumers.
\end{abstract}

Keywords-asset allocation; temporary income shock; heterogeneous consumers; consumption

\section{INTRODUCTION}

In recent years, the household assets of our country have increased rapidly, and the asset structure of the household has the characteristics of diversification. At the beginning of reform and opening up, Chinese residents only owned two forms of financial capital, cash and savings. Since the $21 \mathrm{st}$ century, the household assets include not only financial assets such as stocks and bonds, but also fixed assets such as housing assets, and the proportion of housing assets in total household assets has increased year by year. Residents allocate household assets through multiple channels to increase the wealth.

From 1978 to the end of the 20th century, the average consumption rate of residents in China was $48 \%$. The consumption rate of residents has continued to decline since entering the new century and dropped to $35.9 \%$ in 2010 , which is far below the world average level. The decline of consumption growth will bring downward pressure on economic growth, thus it is urgent to explore the reasons for the low consumption rate in China, so as to enhance the basic role of consumption in the economic growth. According to the life-cycle-permanent income hypothesis, the expansion of household assets and the diversification of asset structure seem to deviate from the low consumption of residents whether in the long term or short term. This paper defines the heterogeneous consumers according to the ratio between the high liquid assets and income, and examines the response of heterogeneous consumers to the temporary income shocks and the wealth effects of the assets on the heterogeneous consumers.

Kaplan et al. (2014) divide the household assets into high liquid assets and low liquid assets, and put forward the concept of HTM consumers who are constrained by liquidity because of the lack of high liquid assets[1]. Jappelli \& Pistaferri (2014)

This paper received financial support from the National Natural Science Foundation of China (No. 71773063), the National Social Science Fund of China (No.17ZDA038) and Shandong Social Science Planning Project (No. 17CJJJ31) show that consumers with less high liquid assets are more vulnerable to liquidity constraints[2]. High liquid assets are represented by stocks. The increase in stock value will stimulate the stockholders to consume, and the fluctuation of stock price will only affect the consumption of households with stock assets, while the consumption of households without stock assets will not be affected. The typical low liquid asset is the housing assets, whose wealth effect is remarkable (Campbell \& Cocco, 2007)[3]. Aladangady (2017) shows that there exists consumption heterogeneity in different housing situations[4]. The wealth effect of the housing asset is affected by the development of credit market. It is significantly negative in the low stage of the development of credit market, and it changes to be positive when the government relaxes the credit policy. The wealth effect is also different for households with different incomes, and the wealth effect of the middle-income household is significantly higher than that of low-income household (Khalifa et al., 2013)[5]. Bostic et al. (2009) show that the wealth effect of higher age group was higher than that of lower age group[6]. Zang Xuheng and Zhang Xin (2018) shows that HTM consumers are more vulnerable to temporary income shocks than non HTM consumers[7]. The above research provides support for further research on the relationship between the Chinese household asset allocation and the heterogeneous consumer behaviors. The rest of the paper is organized as follows. Section II describes the model. Section III presents the data. Section IV is the quantitative analysis. Section V concludes the paper.

\section{MODEL}

A. Estimation of the MPC of the Heterogeneous Consumers under the Temporary Income Fluctuation

We use the method of Blundell et al. (2008) to estimate the marginal propensity to consume (MPC) under the temporary income shock [8]. Assume the income process of household $\mathrm{i}$ during the $t$ period is:

$$
Y_{i, t}=\gamma_{t} X_{i, t}+P_{i, t}+T_{i, t}
$$

$Y_{i, t}$ is the real income which is composed of the observable income $\left(X_{i, t}\right)$ and non-observable income. The observable income $X_{i, t}$ depends on individual characteristics which could change over time. $\gamma_{t}$ indicates the impact of individual characteristics on income. The non-obervable income includes the permanent component $\left(P_{i, t}\right)$ and transitory component $\left(T_{i, t}\right)$. Suppose the permanent income $P_{i, t}$ follows the martingale process : 


$$
P_{i, t}=P_{i, t-1}+\vartheta_{i, t}
$$

Where $\vartheta_{i, t}$ is serially uncorrelated. The transitory income $T_{i, t}$ follows an MA(q) process :

$$
T_{i, t}=\sum_{j=0}^{q} \theta_{j} \varepsilon_{i, t-j}, \theta_{0}=1
$$

Based on the above assumptions, the non-observable income variation equation is:

$$
\Delta Y_{i, t}=\vartheta_{i, t}+\varepsilon_{i, t}
$$

The consumption of residents is a function of income, and the consumption change process of household $i$ during the $t$ period can be expressed as:

$$
\Delta \mathrm{C}_{i, t}=\pi_{i, t} \vartheta_{i, t}+\tau_{i, t} \varepsilon_{i, t}+\zeta_{i, t}
$$

$\pi_{i, t}$ represents the response coefficient of consumption change to persistent income shocks. $\tau_{i, t}$ is the response coefficient of consumption change to temporary income shock. $\zeta_{i, t}$ is a random term. Assume $\vartheta_{i, t}, \varepsilon_{i, t}$ and $\zeta_{i, t}$ are uncorrelated, then the MPC under temporary income shocks can be written as

$$
M P C_{i, t}=\tau_{i, t}=\frac{\operatorname{cov}\left(\Delta C_{i, t}, \Delta Y_{i, t+1}\right)}{\operatorname{cov}\left(\Delta Y_{i, t}, \Delta Y_{i, t+1}\right)}
$$

Suppose consumers could not anticipate future changes in persistent and temporary income, then

$$
\operatorname{cov}\left(\Delta C_{i, t}, \vartheta_{i, t+1}\right)=\operatorname{cov}\left(\Delta C_{i, t}, \varepsilon_{i, t+1}\right)=0
$$

$M P C_{i, t}$ could be the consistent estimate of $\operatorname{cov}\left(\Delta C_{i, t}, \varepsilon_{i, t}\right) / \operatorname{var}\left(\varepsilon_{i, t}\right)$, that is, the regression coefficient of the change of consumption to the change of income during the $t$ period. In the empirical analysis, the demographic characteristic variables are first regressed by household consumption and household income respectively, and the obtained residuals are taken first-order difference. And then the residual consumption change are regressed by the residual income change to estimate the MPC under temporary income shocks.

\section{B. The Test of Wealth Effect of the Assets of the}

\section{Heterogeneous Consumers}

The housing prices have wealth effect on the consumption. This part introduces the log of the current market value of residents' housing ( $\ln P_{\text {house }}$ ) as the core explanatory variable to examine the wealth effect difference of heterogeneous consumers' housing assets. The basic model is:

$$
\ln C=\gamma_{0}+\gamma_{1} \ln Y+\gamma_{2} \ln P_{\text {house }}+\gamma_{3} X+\eta
$$

Where $\ln C$ and $\ln P_{\text {house }}$ represent the $\log$ of total household consumption and house prices respectively. $\ln Y$ is the $\log$ of real income. $X$ is the other explanatory variables affecting household consumption, including the size of the family (familysize), child dependency ratio (child), old-age dependency ratio $($ old $)$, age (age), years of education $(e d u)$ gender(gender), household registration in urban and rural areas $(u-r)$, marital status (mar). When examining how the housing assets affect the residents' consumption, it is necessary to consider the amount of residents' housing ownership. The model introduces the intersection of house price and housing quantity $(\mathrm{k})$, in which $\mathrm{k}=1$ indicates that the family owns multiple properties, and 0 indicates that the family owns only one house.

$$
\ln C=\gamma_{0}+\gamma_{1} \ln Y+\gamma_{2} \ln P_{\text {house }}+\gamma_{3} \ln P_{\text {house }} \cdot k+\gamma_{4} X+\eta
$$

When $\mathrm{k}=0, \gamma_{2}$ represents the wealth effect of the family with one house. When $\mathrm{k}=1, \gamma_{2}+\gamma_{3}$ is the wealth effect of the family with multiple houses.

\section{DATA}

The data used in this paper are from the China Family Panel Studies (CFPS) conducted by the China Social Sciences Survey Center of Peking University. The database contains detailed data on household demographic variables, consumption, assets and income. This paper selects the data of 2010, 2012, 2014 and 2016. In the process of data screening, this paper only selects the sample whose household number has not changed.The explained variable in this paper is household consumption $(C)$, measured by household consumption expenditure. The explanatory variables mainly include household assets $(W)$, household income $(Y)$ and demographic variables $(X)$. The household assets are divided into high liquid assets ( $W_{\text {finance }}$, represented by net financial assets) and low liquid assets ( $W_{\text {house }}$, represented by the net housing assets). When examining the wealth effect of housing assets, we add whether to own a self-housing $(h)$ and the amount of self-occupied house into the explanatory variables. The household demographic variables $(X)$ mainly include family size (familysize), age (age), gender (gender), urban and rural household registration $(u-r)$, marital status (marriage), years of education $(e d u)$, the child dependency ratio (child) and the old-age dependency ratio (old) . We divide the overall sample into three kinds: non-housing consumer, one-house consumer, and multi-house consumer according to the amount of housing that the consumer owns. We further define the heterogeneous consumers based on the proportion of financial assets $\left(W_{\text {finance }}\right)$ to total income $(Y)$. If $W_{\text {finance }} \leq Y / 2$, the consumer faces liquidity constraints during the inspection period and he is a HTM consumer. If $W_{\text {finance }}>Y / 2$, the high liquidity assets are sufficient, and the consumer is a non HTM consumer.

TABLE I DESCRIPTIVE STATISTICS

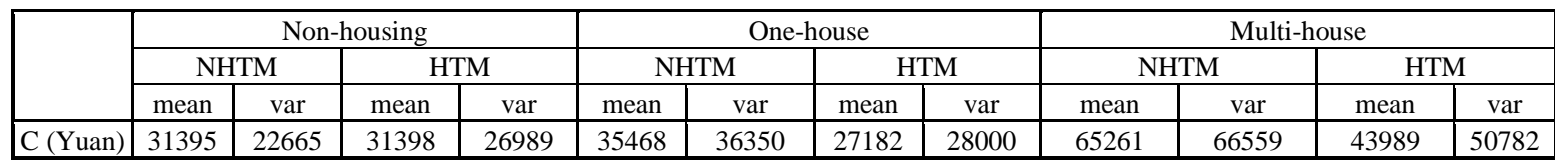




\begin{tabular}{|l|l|l|l|l|l|l|l|l|l|l|l|l|}
\hline Y(Yuan) & 40890 & 29596 & 80399 & 269342 & 43165 & 37811 & 38170 & 58447 & 89570 & 77000 & 66913 & 87306 \\
\hline
\end{tabular}

\section{QUANTITATIVE ANALYSIS}

A. Effects of the High Liquid Assets on the Behaviors of the Heterogeneous Consumers

1) MPC of the HTM and Non HTM Consumers

Table II reports the OLS regression results of the MPC. Model (1) - (8) reflects the estimates of the MPC on the total consumption expenditure (tot), the house (hous), the food, the household equipment and daily expenses (equp), medical care (med), dress (dres), culture and recreation (cul), transportation and communication (tras) in face of the temporary income shocks respectively. The result shows that the consumption of the HTM consumers will be constrained because they don't have enough financial assets. When the current income increases, the HTM consumers will loosen the liquidity constraint and the consumption will increase significantly. Because the non HTM consumers (NHTM) have enough financial assets, they are able to achieve intertemporal optimum and are less affected by the temporary income shocks.

According to model (1), when the temporary income increases by 100 yuan, the total consumption expenditure of HTM consumers will increase by 9.7 yuan, but the effect on non HTM consumers will be smaller. The result of model (2) indicates that, for every 100 yuan increase in temporary income, the expenditure on housing of HTM consumers will increase by 4 yuan, but that of the non HTM consumers will not change significantly. According to model (3) to (8), except for the expenditure on the culture, education and entertainment, the MPC of the HTM consumers on the food, household equipment and daily expenses, medical care, dress, culture and recreation, transportation and communication is significantly positive in face of temporary income shock. The shock doesn't affect the consumption decisions of the non HTM consumers.

2) MPC of the Homeowners and Non-housing Consumers

According to Table III, empirical results show that whether HTM consumers have housing assets or not, the MPC is significantly positive when they face temporary income shocks. Consumers with insufficient holdings of high liquid assets cannot achieve intertemporal optimum, so the increase in current income will significantly increase their current consumption. And when the temporary income increases, the current consumption increases for non-housing and multihouse HTM consumers are much higher than that of one-house HTM consumers. Because the non-housing HTM consumers are constrained by the liquidity of assets, their consumption expenditure is usually to meet the basic living needs. And the increase of current income level will relax the liquidity constraints, so they are most vulnerable to temporary income shocks. For HTM consumers with multiple housings, their consumption is limited by the lack of high liquid assets, but the investment property of this group's housing assets is significant. When faced with temporary income shock, the saving motivation caused by the increase of current income is weak, the liquidity constraint is relaxed, and the marginal consumption tendency under temporary impact is higher. For the HTM consumer who owns one housing, the housing assets' consumer goods attribute is remarkable. When the current income increases, the consumer's savings motive is stronger, the consumption increase is limited, thus the MPC is lower.

TABLE II. Estimates Of THE MPC OF THE HTM AND NON HTM CONSUMERS

\begin{tabular}{|c|c|c|c|c|c|c|c|c|}
\hline & \multicolumn{2}{|c|}{$\begin{array}{c}\text { Model (1) } \\
\Delta \text { tot }\end{array}$} & \multicolumn{2}{|c|}{$\begin{array}{c}\text { Model (2) } \\
\Delta \text { hous }\end{array}$} & \multicolumn{2}{|c|}{$\begin{array}{c}\text { Model (3) } \\
\Delta \text { food }\end{array}$} & \multicolumn{2}{|c|}{$\begin{array}{c}\text { Model (4) } \\
\Delta \text { equp }\end{array}$} \\
\hline & NHTM & HTM & NHTM & HTM & NHTM & HTM & NHTM & HTM \\
\hline \multirow{2}{*}{ constant } & $4046^{* * *}$ & $-1200 * * *$ & $-116^{*}$ & 214 & $940 * * *$ & $-266^{*}$ & $819 * * *$ & -191 \\
\hline & $(16.1)$ & $(-3.0)$ & $(-1.7)$ & (1.6) & $(24.8)$ & $(-1.9)$ & (7.6) & $(-0.7)$ \\
\hline \multirow{2}{*}{$\Delta \mathrm{y}$} & $0.05^{*}$ & $0.097^{* * *}$ & 0.01 & $0.04^{* * *}$ & 0.004 & $0.01^{* * *}$ & 0.01 & $0.03^{* * *}$ \\
\hline & $(1.9)$ & $(9.7)$ & $(1.1)$ & (13.3) & $(1.2)$ & (3.7) & $(1.1)$ & $(4.1)$ \\
\hline $\mathrm{R}^{2}$ & 0.33 & 0.55 & 0.09 & 0.25 & 0.3 & 0.3 & 0.08 & 0.09 \\
\hline \multirow[t]{3}{*}{$\mathrm{F}$} & 3.6 & 94.5 & 1.14 & 177 & 1.4 & 13.9 & 1.2 & 16.7 \\
\hline & \multicolumn{2}{|c|}{$\begin{array}{c}\text { Model (5) } \\
\Delta \text { med }\end{array}$} & \multicolumn{2}{|c|}{$\begin{array}{c}\text { Model (6) } \\
\Delta \text { dres }\end{array}$} & \multicolumn{2}{|c|}{$\begin{array}{c}\text { Model (7) } \\
\Delta \text { cul } \\
\end{array}$} & \multicolumn{2}{|c|}{$\begin{array}{c}\text { Model (8) } \\
\Delta \text { tras } \\
\end{array}$} \\
\hline & NHTM & HTM & NHTM & HTM & NHTM & HTM & NHTM & HTM \\
\hline \multirow{2}{*}{ constant } & $-68^{* * * *}$ & $36^{* * *}$ & $-55^{* * * *}$ & $30^{* * * *}$ & -1.2 & -2.4 & $52^{* * * *}$ & -1.94 \\
\hline & $(-27.7)$ & $(3.8)$ & $(-30)$ & $(4.5)$ & $(-0.3)$ & $(-0.3)$ & $(12.4)$ & $(-0.2)$ \\
\hline \multirow{2}{*}{$\Delta y$} & -0.001 & $0.001^{* *}$ & 0.001 & $0.001^{*}$ & $0.001^{* *}$ & -0.001 & -0.001 & $0.001^{* * *}$ \\
\hline & $(-0.5)$ & $(2.0)$ & $(0.8)$ & $(1.7)$ & $(2.4)$ & $(-0.0)$ & $(-0.4)$ & $(2.8)$ \\
\hline $\mathrm{R}^{2}$ & 0.17 & 0.19 & 0.23 & 0.25 & 0.17 & 0.12 & 0.07 & 0.04 \\
\hline F & 0.20 & 3.97 & 0.61 & 3.04 & 5.57 & 0.00 & 0.18 & 7.63 \\
\hline
\end{tabular}


TABLE III. ESTIMATES OF MPC OF HOMEOWNERS AND NON-HOUSING CONSUMERS

\begin{tabular}{|c|c|c|c|c|c|}
\hline \multirow{2}{*}{} & Non-housing & \multicolumn{2}{|c|}{ One-house } & \multicolumn{2}{c|}{ Multi-house } \\
\cline { 2 - 6 } & $\boldsymbol{H T M}$ & NHTM & HTM & NHTM & HTM \\
\hline \multirow{2}{*}{ constant } & -3200 & -435 & $-2200^{* * *}$ & $24000^{* * *}$ & 160 \\
& $(-1.7)$ & $(-0.6)$ & $(-6.3)$ & $(4.1)$ & $(0.1)$ \\
\hline \multirow{2}{*}{$\Delta \mathrm{Y}$} & $0.507^{* * * *}$ & $0.035^{* *}$ & $0.110^{* * *}$ & 0.008 & $0.481^{* * *}$ \\
& $(5.3)$ & $(2.2)$ & $(11.8)$ & $(0.1)$ & $(5.0)$ \\
\hline $\mathrm{N}$ & 67 & 876 & 2496 & 227 & 406 \\
\hline
\end{tabular}

Notes: * Significant at $10 \%$.* Significant at $5 \%$ ***Significant at $1 \%$.

\section{B. Effects of the Low Liquid Assets on the Behaviors of the} Heterogeneous Consumers

According to the regression results in Table IV, the income, housing price, family size, child dependency ratio, age, years of education and urban and rural household registration status all significantly affect household consumption decision-making. There is a significant difference of the wealth effect between the case of one house and multiple housings. Higher housing prices will significantly increase the consumption level of the consumers who own houses, and the wealth effect of housing assets is significant. The wealth effect of housing assets of non HTM consumers is higher than that of HTM consumers.

TABLE IV. Estimates of THE WeAlth EFFeCt of Heterogeneous CONSUMERS

\begin{tabular}{|c|c|c|c|}
\hline & $\begin{array}{c}\text { (1) } \\
\text { NHTM }\end{array}$ & $\begin{array}{c}(2) \\
\text { HTM }\end{array}$ & $\begin{array}{c}(3) \\
\text { TOTAL }\end{array}$ \\
\hline \multirow{2}{*}{$\ln \mathrm{Y}$} & $0.331^{* * *}$ & $0.340^{* * * *}$ & $0.326^{* * * *}$ \\
\hline & $(12.01)$ & $(19.48)$ & $(21.50)$ \\
\hline \multirow{2}{*}{$\ln \mathrm{P}_{\text {house }}$} & $0.124^{* * *}$ & $0.089^{* * * *}$ & $0.098^{* * * *}$ \\
\hline & $(5.88)$ & $(7.02)$ & $(8.70)$ \\
\hline \multirow{2}{*}{$\ln \mathrm{P}_{\text {house }} \cdot \mathrm{k}$} & $0.020^{* * *}$ & $0.010^{*}$ & $0.015^{* * * *}$ \\
\hline & $(2.34)$ & $(1.75)$ & $(3.03)$ \\
\hline \multirow{2}{*}{ child } & $0.259^{*}$ & $0.522^{* * * *}$ & $0.464^{* * * *}$ \\
\hline & $(1.78)$ & $(8.14)$ & $(7.98)$ \\
\hline \multirow{2}{*}{ familysize } & $0.131^{* * *}$ & $0.064^{* * * *}$ & $0.073^{* * *}$ \\
\hline & $(7.16)$ & $(6.83)$ & $(8.38)$ \\
\hline \multirow{2}{*}{ age } & $-0.014^{* * *}$ & $-0.007^{* * *}$ & $-0.008^{\text {**** }}$ \\
\hline & $(-5.01)$ & $(-4.35)$ & $(-5.11)$ \\
\hline \multirow{2}{*}{ old } & $0.179^{*}$ & 0.013 & 0.031 \\
\hline & $(1.77)$ & $(0.18)$ & $(0.49)$ \\
\hline \multirow{2}{*}{ edu } & $0.028^{* * *}$ & $0.035^{* * *}$ & $0.039^{* * * *}$ \\
\hline & (3.14) & $(6.70)$ & $(8.85)$ \\
\hline \multirow{2}{*}{ gender } & -0.007 & -0.053 & -0.050 \\
\hline & $(-0.10)$ & $(-0.99)$ & $(-1.11)$ \\
\hline \multirow{2}{*}{ mar } & $0.207^{* *}$ & 0.008 & 0.038 \\
\hline & $(2.51)$ & $(0.16)$ & $(0.87)$ \\
\hline \multirow{2}{*}{$\mathrm{u}-\mathrm{r}$} & 0.097 & $0.094^{* * * *}$ & $0.120^{* * * *}$ \\
\hline & $(1.56)$ & $(2.59)$ & $(3.58)$ \\
\hline \multirow{2}{*}{ Constant } & $5.617^{* * * *}$ & $5.609^{* * * *}$ & $5.651^{* * * *}$ \\
\hline & $(17.85)$ & $(28.81)$ & (32.57) \\
\hline $\mathrm{R}^{2}$ & 0.57 & 0.38 & 0.42 \\
\hline $\mathrm{F}$ & 721 & 1259 & 1657 \\
\hline $\mathrm{N}$ & 597 & 2225 & 2822 \\
\hline
\end{tabular}

Notes: * Singnificant at 10\%, ** Significant at 5\%,***Significant at $1 \%$

\section{CONCLUSION}

The results show that: (1) Consumers with insufficient holdings of high liquid assets are more vulnerable to temporary income shocks. Their consumption will increase significantly when the temporary income increases, while the consumption of residents with sufficient high liquid assets does not change significantly. (2) When the house price changes, the wealth effect differs among families. The wealth effect on multi-house families is significantly higher than that of one-house family, and the wealth effect of HTM consumers is higher than that of non HTM consumers. With the rise of the price in the real estate market in recent years, the investment of the housing assets has further squeezed out the financial assets of the residents. The consumers don't hold enough high liquid assets and this reduces the consumption rate to some extent. To promote consumption, the government should push forward the reform of the financial market, supervise the real estate market and stabilize the housing price.

\section{REFERENCES}

[1] Kaplan, G., and G. L. Violante, "A Model of the Consumption Response to Fiscal Stimulus Payments," Econometrica, 2014, 82 (4): 1199-1239.

[2] Jappelli,T., and L. Pistaferri, "Fiscal Policy and MPC Heterogeneity," American Economic Journal: Macroeconomics, 2014, 6(4):107-136.

[3] Campbell, J.Y., J.F.Cocco, "How Do House Prices Affect Consumption? Evidence from Micro Data,"Journal of Monetary Economy, 2007, 54(3): 591-621.

[4] Aladangady,A. "Housing Wealth and Consumption: Evidence from Geographically-Linked Microdata,” American Economic Review, 2017, 107(11): 3415-3446.

[5] Khalifa S, Seck O, Tobing E. "Housing wealth effect: Evidence from Threshold Estimation," Journal of Housing Economics . 2013 (1).

[6] Bostic R, Gabrielb S, Painter G. "Housing Wealth, Financial Wealth, and Consumption: New Evidence from Micro Data," Regional Science and Urban Economics,2009,39(1):79-89.

[7] Zang Xuheng, Zhang Xin, "Household Asset Allocation and Heterogeneous Consumer Behavior in China," Economic Research Journal. 2018,53(03):21-34. (In Chinese).

[8] [8] Blundell, R. , L. Pistaferri, and I. Preston, "Consumption Inequality and Partial Insurance”. American Economic Review, 2008, 98 (5): 1887 $-1921$. 